\title{
PROPOSIÇÕES EM TORNO DE INSTRUMENTOS NÃO JUDICIAIS DE ENFRENTAMENTO À SOLUÇÃO DE CONTINUIDADE DA JUSTIÇA DE TRANSIÇÃO NO BRASIL
}

Isabelle Maria Campos Vasconcelos Chehab ${ }^{1}$

\section{RESUMO}

Discorre sobre propostas de enfrentamento à solução de continuidade da justiça de transição no Brasil. Para tanto, utilizou-se de pesquisa bibliográfica e documental. Primeiramente, fezse uma contextualização da justiça de transição. Na sequência, apresentaram-se tais propostas de enfrentamento, sublinhando-se a necessidade de criar um órgão de seguimento da Comissão Nacional da Verdade e de instituir uma Comissão Regional da Verdade. Ao final, verificou-se da relevância de retomar os debates acerca da justiça transicional no Brasil, considerando que a sua concretização pode contribuir diretamente para a superação dos legados autoritários de outrora e para a construção de uma democracia substancial.

Palavras-chave: Justiça de Transição; Democracia; Direitos humanos; Verdade; Memória.

\section{PROPOSALS AROUND NON-JUDICIAL INSTRUMENTS TO FACE THE CONTINUITY SOLUTION FOR TRANSITIONAL JUSTICE IN BRAZIL}

\begin{abstract}
:
Discusses proposals to face the rupture of transitional justice in Brazil. Therefore, it was used bibliographical and documentary research. Initially, it was done a contextualisation of transitional justice. Subsequently, the proposals were presented, underlining the need to create a follow-up organization of the National Truth Commission and to establish a Regional Truth Commission. By the end, it was verified the relevance of returning the debates about transitional justice in Brazil, considering that their concretization can directly contribute to overcome the authoritarian legacies of the past and to the construction of a substantial democracy.
\end{abstract}

Keywords: Transitional Justice; Democracy; Human Rights; Truth; Memory.

\footnotetext{
${ }^{1}$ Doutora e Mestra em Direito Constitucional pela Universidade de Fortaleza (UNIFOR). Atualmente, é Professora Titular I e Coordenadora do Núcleo de Trabalho de Conclusão de Curso (TCC) da Faculdade ESUP/GO. Atuou como consultora do Programa das Nações Unidas para o Desenvolvimento (PNUD) na Comissão de Anistia do Ministério da Justiça (CA/MJ) para a Rede Latino-Americana de Justiça de Transição (RLAJT). Foi analista de pesquisa do Programa das Nações Unidas para o Desenvolvimento (PNUD) na Comissão Nacional da Verdade (CNV) e membro do seu Comitê de Relatoria. Associada ao Conselho Nacional de Pesquisa e Pós-Graduação em Direito (CONPEDI). Parecerista da Espaço Jurídico: Journal of Law (EJJL) e Membro do Conselho Editorial da Revista Themis (ESMEC/CE).
} 


\section{INTRODUÇÃO}

Nas últimas duas décadas, as políticas públicas direcionadas para a implementação da justiça de transição no Brasil tiveram uma significativa ampliação, especialmente no que concerne aos direitos à reparação, memória e verdade. Entretanto, a partir do segundo semestre do ano de 2015, verificou-se um processo contínuo de desestruturação dos seus órgãos de promoção e defesa, conjugada à expressiva redução do seu orçamento. Malgrado alguns defendam que esta é uma temática restrita aos grupos de sobreviventes e de familiares de mortos e desaparecidos pela ditadura civil-militar, instaurada no Brasil, a partir de 31 de março de 1964, a realidade é que a justiça de transição, por sua própria definição, relaciona-se ao conjunto de mecanismos judiciais e extrajudiciais para tratamento de graves violações de direitos humanos, portanto, diz respeito à humanidade em sua íntegra.

Por semelhante modo, frisa-se que a justiça de transição guarda consigo relevância não apenas no âmbito teórico, como também na seara da práxis dos direitos humanos. Tal temática vincula-se diretamente ao passado brasileiro de graves violações de direitos humanos que, ainda, não conseguimos superar enquanto nação, razão pela qual os seus legados, a exemplo do autoritarismo, da impunidade e da criminalização dos movimentos sociais, costumeiramente retornam ao campo político-institucional por meio de rupturas e transgressões normativas.

O objetivo principal deste artigo é, pois, discorrer sobre a proposição de instrumentos não judiciais de enfrentamento à solução continuidade da justiça de transição no Brasil, com ressalte para a criação de um órgão permanente de seguimento da Comissão Nacional da Verdade (CNV) e para a instalação de uma Comissão Regional da Verdade (CRV). Nesses termos, o texto será dividido em três partes. Na primeira, apresentará uma contextualização histórica e conceitual da justiça de transição. Na sequência, analisará a implementação da justiça de transição no Brasil. Por fim, minudenciará duas propostas concernentes a instrumentos não judiciais que podem colaborar para superar a solução de continuidade da justiça transicional no Brasil.

No que tange à metodologia, aclara-se que esta pesquisa será dotada de caráter eminentemente bibliográfico interdisciplinar, na medida em que, conjugado à doutrina jurídica, serão permeadas a Ciência Política, a Sociologia e a História. Também, registra-se o seu cunho documental, pela utilização de extensa legislação nacional e internacional. De igual modo, deve ser entendida como pesquisa aplicada, considerando o seu intuito de colaborar, por meio dos dados aqui reunidos, para a construção de uma sociedade mais democrática, 
porque cônscia das graves violações de direitos humanos cometidas pela ditadura civil-militar e da premência de sua não-repetição. Ademais, trata-se de ensaio eminentemente qualitativo, dada a sua perspectiva de buscar compreender o contexto do objeto investigado, conforme adiante será explicitado.

\section{JUSTIÇA DE TRANSIÇÃO: CONTEXTUALIZAÇÃO CONCEITUAL E HISTÓRICA}

Conforme Ruti Teitel (2003, p. 69-70), a expressão justiça de transição guarda suas raízes na Primeira Guerra Mundial, entretanto, somente se torna "extraordinária e internacional", com o término da Segunda Guerra Mundial, em 1945, a partir de quando foi vislumbrada a necessidade de reflexão sobre as graves violações de direitos humanos ali perpetradas, e, consequentemente, da implementação de mecanismos para saná-las, por meio da restauração do tecido social e da promoção da dignidade da pessoa humana.

Na sequência, durante a década de 60 do século XX, o sul da Europa protagonizou diversas medidas transicionais, senão vejamos:

\footnotetext{
A Grécia realizou julgamentos e saneamentos, incluindo o julgamento daqueles que lideraram o golpe de 1967 e o 'regime dos coronéis'. Em Portugal houve saneamentos em massa, apesar de seus efeitos serem mais tarde anulados ou revertidos. A Espanha, por sua vez, optou pela anistia e institucionalizou o 'esquecimento' no que diz respeito às atrocidades da Guerra Civil e à subsequente ditadura de Franco. (BRITO, 2009, p. 60).
}

Por sua vez, no curso das décadas de 80 e 90 do século XX, o conceito justiça de transição começou a ganhar visibilidade na Europa Central e no Leste Europeu (BRITO, 2009, p. 60); assim como na África do Sul, com o fim do apartheid e a instalação da sua Comissão da Verdade e Reconciliação (CVR) (ZAMORA, 2012, p. 105); e na América Latina, com o progressivo declínio dos seus regimes autoritários e as suas consequentes demandas por reconstrução democrática. (LEAL, 2012, p. 189).

A despeito disto, a organicidade da justiça de transição, no que tange ao seu conceito, medidas/pilares e implementação, deu-se, apenas, na última década do século XX, a saber:

No decorrer da última década, o campo da justiça transicional se ampliou e se desenvolveu em dois sentidos importantes. Em primeiro lugar, os elementos da justiça transicional passaram de uma aspiração do imaginário à expressão de obrigações legais vinculantes. O direito internacional, particularmente na aplicação a ele dada em organismos como o Tribunal Europeu dos Direitos Humanos, a Corte Interamericana de Direitos Humanos e o Comitê de Direitos Humanos, evoluiu com 
o passar dos últimos vinte anos até o ponto em que atualmente existem padrões claros relativos às obrigações dos Estados a respeito da forma de enfrentar as violações dos direitos humanos, bem como proibições, como no caso das anistias gerais quando se trata de crimes internacionais. [...] Em segundo lugar, o fortalecimento da democracia em muitos lugares do mundo, em especial na América Latina, Ásia e África e o surgimento de organizações cada vez mais sofisticadas da sociedade civil têm contribuído para fundar as instituições e a vontade política necessária para confrontar um legado de violações dos direitos humanos e conseguir que as políticas se traduzam em ações. (ZYL, 2011, 47-48).

Em termos conceituais, pode-se afirmar que a justiça de transição diz respeito a um conjunto de mecanismos e estratégias que tem por intuito colaborar para a transição, tanto em caráter fático, como simbólico, de um regime de exceção e/ou conflitos armados para uma prospecção democrática. Destarte, a expressão propriamente dita é fruto da:

junção de demandas por justiça e por transição democrática foi cunhado para expressar métodos e formas de responder sistemáticas e amplas violações aos direitos humanos. Assim, justiça transicional não expressa nenhuma forma especial de justiça, mas diversas iniciativas, que têm por intuito reconhecer o direito das vítimas, de promover a paz, facilitar a reconciliação e garantir o fortalecimento da democracia. (PINTO, 2010, p. 129, grifou-se).

Por semelhante modo, pontua-se que:

La justicia de transición, tal como es entendida en este estudio, comprende el entero ámbito de los procesos y mecanismos asociados con los intentos de una sociedad para afrontar un legado de abusos a gran escala del pasado, para asegurar responsabilidad, rendir justicia y lograr una reconciliación. Aunque un cambio de régimen no es para nada un fenómeno nuevo, el concepto de justicia de transición es reciente e innovador en cuanto reconoce la importancia de la 'justicia' en los procesos de transición; brevemente, justicia de transición trata de la justicia en la transición. (AMBOS, 2009, p. 26).

Assim, pode-se asseverar que a justiça de transição - ou justiça transicional - carrega consigo o firme propósito de promover a transição de um regime autoritário e/ou conflito armado para um Estado democrático de direito, o que engloba a implementação de diversas medidas e/ou estratégias, tais como: reparação, respeito à memória, promoção da verdade e da justiça e reformas institucionais, todos com vistas à (re)construção de uma genuína democracia.

Convém sublinhar, ainda, que o conjunto de mecanismos de justiça transicional não se propõe a encorajar revanchismos de um grupo - ou segmentos da sociedade - em face dos demais. Pretende, isto sim, colaborar para a construção de uma paz democrática, o que enseja, um efetivo desvelo e enfrentamento das graves violações de direitos humanos outrora praticadas durante regimes de exceção, entendendo que as suas consequências, sobretudo a 
violência institucional, representada pelas arbitrariedades e pelas impunidades dos agentes da repressão, quando não tratadas, tendem a revigorarem-se e reproduzirem-se por todo o tecido social, inclusive, na atualidade. (FREUD, 1989, p. 152).

Destarte, genericamente, há que se refletir sobre quais parâmetros seguir para uma efetiva transição. Primeiramente, defende-se que nenhum dos mecanismos transicionais deve ser menosprezado, tampouco sobrestimado, uma vez que entre a memória, a verdade, a justiça, a reparação e a reforma das instituições não há um escalonamento qualitativo. De fato, o que se tem, por inconteste, é que sem a implementação de todos esses mecanismos conjuntamente não se pode afirmar da existência de uma genuína transição. (ZYL, 2011, p. 65). Em segundo lugar, sustenta-se que seja permanente a presença da sociedade civil durante todo o processo transicional, no sentido de monitorar as suas instâncias discursivas e decisórias, bem como de participar do fluxo (e do influxo) de informações acerca da temática. Objetivamente, quanto mais participativa for a sociedade nesse processo, mais efetiva será a transição. (ZYL, 2011, p. 65-66). Em terceiro lugar, deve-se ter em conta as propostas de reconciliação nacional e de um possível envolvimento/colaboração internacional, firmadas no Relatório $n^{\circ} \mathrm{S} / 2004 / 616$ da ONU, considerando, todavia, seus pontos positivos e negativos e sua adequação para cada caso em concreto, especialmente com o princípio fundamental da soberania. Por fim, não deve ser olvidado que a transição é via de aperfeiçoamento para uma democracia substancial, porque qualitativa e genuína, guardando especial destaque para as vítimas, consoante os seguintes termos: "Pensar sobre o direito das vítimas deve significar não o fim do direito dos agressores, não a imposição do desejo de vingança, mas a restauração da verdade, a concretização da justiça”. (BARTOLOMÉ RUIZ, 2009, p. 177).

\section{JUSTIÇA DE TRANSIÇÃO NO BRASIL}

No Brasil, em específico, as medidas de justiça de transição relacionam-se, principalmente, ao enfrentamento do legado de graves violações de direitos humanos praticadas durante a ditadura civil-militar, instaurada por meio do golpe de Estado de 31 de março de 1964, em face do então presidente João Belchior Marques Goulart, e formalmente vigente até a posse do presidente José Sarney de Araújo Costa, na data de 15 de março de 1985.

Nesses termos, a Lei $\mathrm{n}^{\circ}$ 6.683, de 28 de agosto de 1979, conhecida como Lei de Anistia, foi a primeira medida de transição levada a cabo pelo Estado brasileiro, resultado de um 
histórico de reivindicações encampadas por diversos segmentos da sociedade civil, sobretudo por familiares de presos e de exilados políticos, integrantes de movimentos eclesiásticos de base, estudantes e representantes sindicais. (DEL PORTO, 2009, p.61) Tais ações reivindicavam uma anistia ampla, geral e irrestrita, entretanto, o então Projeto de Lei encaminhado ao Congresso Nacional em junho de 1979, e, em seguida, aprovado, foi deveras restritivo, porque cuidadosamente controlado pelos militares e pelos seus políticos aliados (FICO, 2010, p. 319), ou como afirmado por Jessie Jane Vieira de Sousa (2011, p. 208), referindo-se à redemocratização como um todo: “[...] tutelada pelos militares e pactuada pelas elites”. A utilização dessa estratégia permitiu, pois, a aprovação de uma Lei de anistia, ou autoanistia, restritiva em relação aos que exerceram o seu direito de resistência, ${ }^{2}$ em face do regime ditatorial, especificamente no que tange aos chamados "crimes de sangue", e, por outro lado, demasiadamente parcimoniosa para com os agentes da repressão, que, até a presente data, por força de decisão colegiada do STF, no bojo da Argüição de Descumprimento de Preceito Fundamental (ADPF) n. $153^{3}$, podem alegar que os crimes outrora cometidos, independentemente de sua natureza, portanto, estupros, sequestros, homicídios e latrocínios, tinham natureza política ou motivação política, o que lhes garante escusa legal, espécie de perdão político prévio, ou seja, uma impunidade quase que irrestrita, em razão da interpretação ultraextensiva providenciada pela Lei de Anistia.

Após um longo lapso legislativo transicional, foi criada a Comissão Especial sobre Mortos e Desaparecidos Políticos (CEMDP), por meio da Lei $n^{\circ}$ 9.140, de 4 de dezembro de 1995, que se revestiu de grande relevância histórica, na medida em que representou o primeiro esforço institucional - e perene - do Estado brasileiro de promover a busca e o reconhecimento dos mortos e desaparecidos políticos, e, assim, concretizar uma dos mais milenares direitos do ser humano pertinente às dimensões da verdade e da memória, qual seja: prantear, reconhecer e enterrar os seus mortos (BRASIL, 1995, online). Com fundamento na

${ }^{2}$ Aqui a expressão é utilizada consoante firmado por Santo Tomás de Aquino (1225-1274), em suas obras Suma Teológica, Regime dos Príncipes e Comentários às Sentenças de Pedro Lombardo. Já Buzanello (2002, p. 22) afirma que o direito de resistência se constitui no "direito de cada pessoa, grupo organizado, de todo povo, ou de órgãos do Estado, de opor-se com os meios possíveis, inclusive a força, ao exercício arbitrário e injusto do poder estatal". Tal expressão não deve ser confundida com desobediência civil, vez que esta, conforme Rocha (2010, p. 77-78) é definida- juntamente com a revolução - como sendo espécie do direito de resistência, tendo caráter pacífico, não "almeja a derrubada da ordem vigente, mas, sim, o seu aperfeiçoamento."

${ }^{3}$ No dia 29 de abril de 2010, o STF, a partir do voto do relator da ADPF 153, o então Ministro Eros Grau, "entendeu que a anistia de 1979 era abrangente e também anistiava os agentes do Estado que torturaram e mataram opositores do regime militar entre 1964 e 1985, portanto, estes não eram passíveis de processo ou mesmo objeto de qualquer punição”. (TELES; SAFATLE, 2010, p. 39-40). 
lei supramencionada, foram oportunizadas investigações, apurações e buscas de corpos, que, em sua reta final, registraram 450 (quatrocentos e cinqüenta) pessoas, dentre mortos e desaparecidos políticos (BRASIL, 2007, p. 48).

Na sequência, deve ser sublinhada a criação da Comissão de Anistia (CA), por meio da Medida Provisória n ${ }^{\circ} 2.151-3$, de 24 de agosto de 2002, posteriormente, convertida na Lei $\mathrm{n}^{\circ}$ 10.559, datada de 13 de novembro de 2002, que assumiu por finalidade examinar os requerimentos fundamentados neste diploma legal, para fins de reparação e anistia, e, simultaneamente, assessorar o respectivo Ministro de Estado em suas decisões, no âmbito do Ministério da Justiça, conforme dispõe o seu art. 12. Desde a sua criação, conforme dados do site oficial do Ministério da Justiça, tal Comissão recebeu um número aproximado a 75.000 requerimentos de reparações econômicas, dos quais mais de 60.000 já foram devidamente apreciados. (BRASIL. Ministério da Justiça, 2017, online) Concomitantemente, em 2008, foi idealizado o Programa Caravana da Anistia, responsável por trazer a público, de modo itinerante, os julgamentos da Comissão de Anistia, para fins de cumprimento das medidas transicionais de reparação e memória, já tendo alcançado, sua $93^{a}$ sessão, até dezembro de 2016. A Comissão de Anistia também levou a cabo o Projeto Marcas da Memória, que costumava atuar, basicamente, em quatro campos, quais sejam, audiências públicas; História Oral; Chamadas Públicas de fomento a iniciativas da Sociedade Civil; e Publicações. Nesse contexto, "promove sessões públicas e gratuitas de filmes, dedicados à memória e à reflexão crítica sobre os regimes de exceção vividos na América do Sul, em especial no Brasil, e seus reflexos no presente.” (BRASIL. Ministério da Justiça, 2015, online). Ainda, mais recentemente, em 2012, foram criadas, sob a égide da Comissão de Anistia, as chamadas Clínicas de Testemunho, que visavam "a implantação de núcleos de apoio e atenção psicológica aos afetados pela violência de Estado entre os anos de 1946 e 1988. A execução do projeto se dá por meio de parcerias com a sociedade civil, e contempla três dimensões: atenção a vítimas, capacitação de profissionais e formulação de insumos de referência". (BRASIL. Ministério da Justiça, 2015, online).

Finalmente, em 2009, rompeu-se com a lacuna transicional relacionada ao direito à verdade, quando, na Conferência Nacional de Direitos Humanos, foram estabelecidas, por meio do Programa Nacional de Direitos Humanos III (PNDH 3), no seu Eixo orientador VI, intitulado Direito à Memória e à Verdade, diversas diretrizes, dentre as quais citam-se: Diretriz 23 - Reconhecer da verdade e da memória como direito humano da cidadania e dever 
do Estado; Diretriz 24 - Preservação da memória histórica e a construção pública da verdade; Diretriz 25 - Modernização da legislação relacionada com o direito à memória e à verdade, fortalecendo a democracia (BRASIL, 2010, p.173;176). Naquele mesmo ano de 2009, foi criado um grupo de trabalho composto por membros do Ministério da Justiça, da Secretaria de Direitos Humanos, da Casa Civil da Presidência da República, do Ministério da Defesa e da sociedade civil organizada para elaborar uma minuta de projeto de lei que instituísse a Comissão Nacional da Verdade (SÃO PAULO, 2011, p. 9) Em seguida, o Projeto de Lei $n^{\circ}$ 7.376, de autoria do Poder Executivo, que regulamentou o PNDH III, instituindo uma Comissão Nacional da Verdade, tramitou no Congresso Nacional, entre maio de 2010 e outubro de 2011. Até que em 18 de novembro de 2011, a Comissão Nacional da Verdade $(\mathrm{CNV})$ foi criada, por meio da Lei $\mathrm{n}^{\circ} 12.528$, no âmbito da Casa Civil da Presidência da República, com a finalidade de examinar e esclarecer as graves violações de direitos humanos praticadas no período fixado no art. $8^{\circ}$ do Ato das Disposições Constitucionais Transitórias, qual seja de 18 de setembro de 1946 a 5 de outubro de 1988, a fim de efetivar o direito à memória e à verdade histórica e promover a reconciliação nacional.

Destarte, no dia 16 de maio de 2012, a CNV foi instalada, no intuito de cumprir com os objetivos firmados no art. $3^{\circ}$., da Lei $n^{\circ} 12.528 / 2011$. Somados aos seus sete comissionados, a CNV contou com o auxílio de catorze assessores especializados, conforme o disciplinado pelo art. $9^{\circ}$., da Lei $n^{\circ} 12.528 / 2011$, além de um número superior a 200 pessoas, entre servidores provenientes dos mais diversos ministérios e órgãos, aliados a pesquisadores oriundos de acordo técnico firmado com o Programa das Nações Unidas para o Desenvolvimento (PNUD). (BRASIL, 2014, online) Durante o seu mandato legal, a CNV valeu-se do acúmulo documental já sistematizado pelo Arquivo Nacional (AN), pela Comissão Especial sobre Mortos e Desaparecidos (CEMDP) e pela Comissão de Anistia (CA) (BRASIL, 2014, p. 5860). Em adição, coletou 1.116 depoimentos de vítimas e agentes da repressão, sendo 483 em audiências públicas e 633 em caráter reservado (BRASIL, 2014, p. 55), conjugados aos relatórios e às informações amealhadas pelas comissões estaduais e setoriais. (BRASIL, 2014, p. 55). Para além de seus grupos de trabalho especializados, ${ }^{4}$ a $\mathrm{CNV}$ estruturou equipes

\footnotetext{
${ }^{4}$ Para fins de esclarecimentos, "A partir de dezembro de 2012, as atividades de pesquisa da CNV passaram a ser desenvolvidas basicamente por meio de grupos de trabalho coordenados pelos membros do Colegiado, contando, cada um deles, com assessores, consultores ou pesquisadores. Tal forma de organização teve por intuito permitir a descentralização das investigações e a autonomia das equipes de pesquisa. Pautada nessas diretrizes iniciais, a CNV estabeleceu 13 grupos de trabalho, segmentados pelos seguintes campos temáticos: 1) ditadura e gênero; 2) Araguaia; 3) contextualização, fundamentos e razões do golpe civil-militar de 1964; 4) ditadura e sistema de Justiça; 5) ditadura e repressão aos trabalhadores e ao movimento sindical; 6) estrutura de repressão; 7) mortos e
} 
internas de comunicação, ouvidoria, diligências e perícias. De acordo com o art. 10, da Lei n. 12.528/2011, a CNV gozou de um breve prazo de funcionamento, inicialmente, previsto em 2 (dois) anos, mas que alcançou, nos termos da Medida Provisória $n^{\circ}$ 632/2013, convertida na Lei $n^{\circ}$ 12.998/2014, 2 (dois) anos e 7 (sete) meses, contados da data de sua instalação, até a conclusão dos seus trabalhos, quando foi apresentado, em 10 de dezembro de 2014, um relatório final circunstanciado contendo as atividades realizadas, os fatos examinados, as conclusões e recomendações, por meio do qual reconheceu: 434 pessoas como mortas e desaparecidas durante o lapso fixado pelo art. 1o.,da Lei n. 12.528/2011; 377 agentes/responsáveis - formais e/ou materiais - por graves violações de direitos humanos; além de 229 instituições e locais associados a graves violações de direitos humanos durante a ditadura civil-militar, entre unidades militares e policiais e centros clandestinos.

Ainda, no âmbito da medida transicional intitulada de justiça tem-se como um de seus maiores desafios a persistência do reconhecimento de constitucionalidade da Lei de Anistia, que, diferentemente do protagonizado pela Argentina, Chile e Uruguai, tem impossibilitado o seguimento da ampla maioria das demandas judiciais criminais, malgrado o intenso trabalho desenvolvido com especial destaque pelo Ministério Público Federal (MPF) para punir os agentes da repressão. Nesses termos, conforme Relatórios de Atuação - Crimes da Ditadura (BRASIL, 2017, p. 25-26), até dezembro de 2016, o MPF “(...) propôs 27 ações penais contra 47 agentes envolvidos em 43 crimes cometidos contra 37 vítimas. São listados 11 homicídios, 9 falsidades ideológicas, 7 sequestros, 6 ocultações de cadáver, 2 quadrilhas armadas, 2 fraudes processuais, 1 estupro, 1 favorecimento pessoal, 1 transporte de explosivos, 1 lesão corporal e 2 abusos de autoridade.” Desses, tem-se que, na $1^{a}$. Instância, 17 decisões foram desfavoráveis, enquanto 4 foram deferidas. Já na $2^{\text {a }}$. Instância, os números desfavoráveis são 7 contra 2 decisões favoráveis. Por seu turno, no Superior Tribunal de Justiça (STJ), há 3 decisões contrárias e nenhuma favorável aos pleitos do MPF. (BRASIL, 2017, p. 28) A possibilidade de romper com esse ciclo de perdas no Poder Judiciário em matéria transicional ocorre, todavia, no âmbito cível, onde os pedidos de acesso à informação; esclarecimentos dos fatos; pleitos de indenização apresentados por vítimas e familiares; ações declaratórias para reconhecimento judicial da responsabilidade institucional do Estado ou pessoal de autores de graves violações de direitos humanos; de retificação de certidões de óbito; alteração de

desaparecidos políticos; 8) graves violações de direitos humanos no campo ou contra indígenas; 9) Operação Condor; 10) papel das igrejas durante a ditadura; 11) perseguições a militares; 12) violações de direitos humanos de brasileiros no exterior e de estrangeiros no Brasil; e 13) o Estado ditatorial-militar.” (BRASIL, 2014, p. 51). 
nomes de vias públicas; e de proteção do direito à verdade e à memória em sua dimensão coletiva têm sido constantemente objeto de processamento e condenação pelo Poder Judiciário mediante reparação pecuniária e simbólica em favor das vítimas e/ou familiares de mortos e/ou desaparecidos políticos. (OSMO, 2016, p. 73-90).

A partir de 2015, com o enfraquecimento político do poder executivo federal capitaneado pela centro-esquerda brasileira, em especial pelo Partido dos Trabalhadores (PT), sobretudo devido as sistemáticas denúncias produzidas e disseminadas no bojo da intitulada Operação Lava-Jato ${ }^{5}$, verificou-se um movimento de involução na implementação do conjunto de medidas transicionais no Brasil. Os nossos avanços, no âmbito transicional, embora que diminutos, se comparados aos nossos vizinhos do Cone Sul (PEREIRA, 2010, p.58), tornaram-se quase inócuos com o processo de derrocada do governo central do PT. Objetivamente, já no ano de 2015 observou-se um decréscimo no orçamento destinado às políticas públicas de direitos humanos na ordem de quase 20\%, se comparado ao ano de 2014 (BRASIL, 2016, online). Tal lógica fora imediatamente seguida pelos aportes federais referentes à execução de políticas públicas de promoção da justiça de transição e anistia política, os quais foram suprimidos, em 2016, para $\mathrm{R}$ \$3.638.312,00 (três milhões seiscentos e trinta e oito mil e trezentos e doze reais), ou seja, o menor orçamento na seara da Justiça, Cidadania e Segurança do Ministério da Justiça. Já em 2016, houve uma redução ainda mais ampla para as políticas de promoção e defesa dos direitos humanos no âmbito federal, a saber: na ordem de 50\%. Em termos numéricos, o projeto orçamentário federal de 2015 alcançou R\$ 8.000.000,00 (oito milhões), enquanto que em 2016 o orçamento foi de, apenas, R\$ 5.000.000,00 (cinco milhões) para a execução das mesmas políticas, pela então Secretaria de Direitos Humanos, atual Ministério da Justiça e Cidadania, conforme minudencia o Projeto de Lei Orçamentária - exercício de 2016 (BRASIL, 2016, online).

Somados aos aspectos orçamentários, a mesma Comissão de Anistia/MJ sofreu reveses outros, especialmente no que concerne à formação do seu órgão colegiado, que analisa e delibera acerca das indenizações relacionadas às vítimas de graves violações de direitos

\footnotetext{
${ }^{5}$ De acordo com o sítio oficial do Ministério Público Federal (MPF), o nome Operação Lava Jato "decorre do uso de uma rede de postos de combustíveis e lava a jato de automóveis para movimentar recursos ilícitos pertencentes a uma das organizações criminosas inicialmente investigadas. Embora a investigação tenha avançado para outras organizações criminosas, o nome inicial se consagrou." No mesmo sítio, tal operação Lava Jato é intitulada como "(...) a maior investigação de corrupção e lavagem de dinheiro que o Brasil já teve. Estima-se que o volume de recursos desviados dos cofres da Petrobras, maior estatal do país, esteja na casa de bilhões de reais. Soma-se a isso a expressão econômica e política dos suspeitos de participar do esquema de corrupção que envolve a companhia." (MPF, ONLINE, 2017)
} 
humanos durante o período de 1946 a 1988, e, por força das Portarias n. 792 e 793, ambas de 31 de agosto de 2016, assinadas pelo então Ministro da Justiça e Cidadania, ora Ministro do STF, Alexandre de Moraes, foi submetida à intervenção direta, que ensejou a dispensa de 19 (dezenove) dos seus 25 (vinte e cinco) conselheiros, substituídos, dentre figuras anônimas na seara transicional, por uma pessoa que supostamente esteve vinculada a graves violações de direitos humanos durante a ditadura civil-militar brasileira. (CRUVINEL, 2016, online)

\section{PROPOSTAS DE ENFRENTAMENTO À SOLUÇÃO DE CONTINUIDADE DA JUSTIÇA DE TRANSIÇÃO NO BRASIL}

Malgrado fosse possível tecer comentários sobre diversas propostas de enfrentamento à solução de continuidade da justiça de transição no Brasil, entendeu-se por centralizar tais sugestões em duas linhas distintas, mas que conjugadas podem colaborar sensivelmente para uma retomada eficaz dos debates teórico-práticos em torno da justiça transicional, a saber: a primeira está voltada para o nicho de políticas públicas de Estado, portanto, aquelas planejadas e desenvolvidas em caráter permanente para concretizar direitos humanos; a segunda está focada nas execução de uma política supranacional, que, mais especificamente, encontra-se em franco alinhamento com as demandas regionais pertinentes aos direitos humanos do Cone Sul.

Destarte, a primeira proposta de enfrentamento à solução de continuidade da justiça de transição no Brasil aqui declinada guarda suas raízes nas recomendações do Relatório final da $\mathrm{CNV}$, especialmente no que tange à sugestão de criar um órgão permanente com atribuição para dar seguimento às ações e às recomendações da $\mathrm{CNV}$, concernentes à promoção e defesa do direito à verdade e à memória. (BRASIL, 2014, p. 973)

Com o advento do término do mandato legal da CNV, esse propósito passou a ganhar forma por meio da Portaria Interministerial n. 4, de 11 de maio de 2016, assinada pelo então Ministro da Justiça Eugênio José Guilherme de Aragão, que dispôs sobre a instituição de Grupo de Trabalho Interministerial para analisar a criação de órgão permanente e de mecanismos de monitoramento relativos à Comissão Nacional da Verdade, direcionado, nos termos do seu art. $1^{\circ}$., para os seguintes aspectos: I - ações e mecanismos para dar continuidade à apuração dos fatos e à busca da verdade sobre a prática de detenções ilegais e arbitrárias, tortura, execuções, desaparecimentos forçados e ocultação de cadáveres; II propor, junto aos órgãos competentes, o prosseguimento na investigação de eventos e 
condutas cuja apuração não tenha sido concluída pela Comissão Nacional da Verdade; III propor, junto aos órgãos competentes, atividades de investigação documental com pessoas, instituições e organismos, públicos e privados, afetos à temática; IV - propor atividades de informação sobre as graves violações de direitos humanos no país e no exterior; V - propor medidas que apoiem a reparação coletiva pelas graves violações sofridas pela população camponesa e pelos povos indígenas no período investigado pela Comissão Nacional da Verdade; e VI - propor ações ou políticas públicas destinadas a prevenir violação de direitos humanos e assegurar sua não repetição.

Tal iniciativa, entretanto, findou por não lograr êxito, uma vez que três meses após a sua instituição, a Presidenta Dilma foi submetida ao impedimento que lhe retirou da Presidência da República, fato que engendrou também a extinção dos efeitos da supramencionada Portaria e uma posterior reconfiguração institucional e finalística do Ministério da Justiça e da Secretaria Especial de Direitos Humanos, hoje reunidos no intitulado Ministério da Justiça e Cidadania, que não incluiu no seu rol de prioridades qualquer tópico relacionado à implementação de políticas públicas de ordem transicional.

A despeito da atual lacuna normativa que margina o tema, entende-se que tal órgão de seguimento seria de grande valia para a concretização da justiça transicional no Brasil, uma vez que aglutinaria em torno de si não apenas as atividades já em vias de desenvolvimento pela CNV, como também poderia fazer uso de novas frentes de trabalho, direcionadas, por exemplo, para o acompanhamento e execução de perícias pertinentes a casos emblemáticos de graves violações de direitos humanos ocorridos durante a ditadura civil-militar, ou que sobre os quais ainda repousassem dúvidas quanto às suas versões oficiais. Por semelhante modo, esse órgão de seguimento poderia encampar a meta de gradualmente implementar as 29 (vinte e nove) recomendações da $\mathrm{CNV}$, em especial aquelas voltadas para a educação em direitos humanos e democracia, temáticas que, de modo direto e/ou transversal, já encontram guarida em outros órgãos do governo federal, estadual e municipal, e poderia ser potencializadas pela instituição de programas e projetos específicos em justiça de transição. Igualmente, o órgão federal de seguimento ora em discussão poderia revitalizar as mais de 100 comissões estaduais, municipais e setoriais instaladas durante o mandato legal da $\mathrm{CNV}$, com o propósito de, assim, agremiar forças nos âmbitos local e regional, e, consequentemente, trazer visibilidade para os debates em torno dos pilares transicionais, sobretudo no pertinente à verdade, memória e justiça. 
Ainda, convém sublinhar que essa proposta em torno de um órgão de seguimento para a

CNV não é propriamente uma novidade à brasileira, uma vez que diversos países submetidos a Comissões da Verdade fizeram uso de semelhante instituto. Para nós, um dos exemplos mais próximos diz respeito ao Uruguai, que, por meio da Resolución Presidencial n. 449, de 10 de abril de 2003, promoveu a instalação da Secretaria de Derechos Humanos para el Pasado Reciente (URUGUAY, 2017, online), com o objetivo de tratar em caráter permanente as graves violações de direitos humanos cometidas na vigência da ditadura militar uruguaia. Tal órgão é entendido como política pública do Estado uruguaio, o que lhe garante um funcionamento contínuo, independentemente do partido que esteja ocasionalmente exercendo o poder central. Nesse contexto, a Secretaria de Derechos Humanos para el Pasado Reciente merece ressalte não apenas pela sua proximidade geográfica com o Brasil, mas principalmente pelo seu trabalho de caráter qualitativo e continuado. Por derradeiro, aclara-se que a exposição dos dados uruguaios não tem o condão de impor uma transposição direta da estrutura da Secretaria de Derechos Humanos para el Pasado Reciente para a realidade brasileira, entretanto, entende-se que os mesmos podem ser utilizados como elementos norteadores para a implantação adequada de um órgão de seguimento transicional de alto nível no Brasil.

$\mathrm{Na}$ sequência, apresenta-se como segunda proposta de enfrentamento à solução de continuidade da justiça de transição no Brasil a criação de uma Comissão Regional da Verdade (CRV), que assumiria por finalidade investigar conjuntamente as graves violações de direitos humanos cometidas no Cone Sul na vigência de suas ditaduras, durante as décadas de 60 e 90 do século XX, tendo por marco principal - e comum - a Operação Condor. Tal Operação teve seu início formal em novembro de 1975, entretanto, há indícios da prática e/ou auxílio de crimes comuns, a partir do início dos anos 1970. (BRASIL, 2014, p. 232). A Condor caracterizou-se por ser uma espécie de "esquadrão da morte internacional" (GASPARI, 2004, p.381), que tinha por objetivos principais a centralização de informações e o extermínio dos resistentes dos regimes de exceção latinos, notadamente Argentina, Bolívia, Brasil, Chile, Paraguai e Uruguai ${ }^{6}$. (BRASIL, 2014, p. 220) Malgrado ainda sejam pouco discutidas a extensão de letalidade e o grau de sofisticação da Operação Condor, tem-se por estimado que a mesma provocou cerca de 10.000 vitimados - diretos e/ou indiretos - em toda a América Latina. (ALMADA, 2013, p. 243). Ademais, é importante esclarecer que tal

\footnotetext{
${ }^{6}$ Conforme declinado no Relatório Final da CNV (2014, p. 221), Bolívia e Peru ingressaram posteriormente na Operação Condor, provavelmente, no ano de 1978.
} 
Operação não foi implementada isoladamente na América Latina, mas contou com o apoio massivo dos Estados Unidos da América (EUA), especialmente no que tange ao seu aparato logístico e tecnológico (BRASIL, 2014, p. 222), que colaborou também para a deflagração dos golpes militares na Argentina (PRIORI, 2006, p.1), no Brasil (BRASIL, 2014, p. 97) e no Chile (GASPARI, 2002, p. 302; p.371-372).

A hodierna argumentação advém de provas robustas, consubstanciadas pela sociedade civil $^{7}$, pelos judiciários locais ${ }^{8}$ e pela própria Corte Interamericana de Direitos Humanos $(\mathrm{CorteIDH})^{9}$, que, conjuntamente, demonstram que muitas das graves violações de direitos humanos praticadas contra os resistentes das ditaduras latinas, a partir dos anos 1970, estavam vinculadas pela Operação Condor, seja no seu planejamento e/ou execução, direcionadas prioritariamente para o extermínio dos seus inimigos comuns, portanto, daqueles que se opunham aos regimes de exceção implementados na região.

Nesses termos, investigar a Operação Condor por meio de um órgão comum latino, intitulado de Comissão da Verdade Regional ou entidade que lhe seja assemelhada, tornaria possível um ideal antigo dos defensores da democracia e sobreviventes das ditaduras na região, qual seja, publicizar e comprovar documentalmente as graves violações de direitos humanos cometidas e patrocinadas pelas ditaduras do Cone Sul, tornando cônscias as gerações presentes e vindouras dos seus prejuízos para a democracia, para a institucionalidade e para o povo latinos. Por semelhante, tal Comissão poderia promover ações conjuntas de educação em direitos humanos, que, inclusive, já estejam sendo implementadas em um - ou alguns - dos países atingidos pelas ditaduras de outrora, passando, pois, agora, por etapas de discussão, análise e aperfeiçoamento, com vistas à promoção de políticas públicas comuns relacionadas ao direito à verdade, memória e reforma das instituições. Igualmente, observa-se que a criação de uma eventual CVR poderia facilitar a aquisição de indícios e/ou provas documentais, periciais e testemunhais, para auxiliar no desvelo de graves violações de direitos humanos praticadas, planejadas e/ou conhecidas no curso da Operação Condor que, inclusive, possam estar tramitando na seara judicial. Ainda, defende-se que a instalação de uma CVR poderia fortalecer o impacto na sociedade civil acerca das políticas públicas e das

\footnotetext{
7 A maior parte das provas até hoje amealhadas sobre a Operação Condor foram encontradas, em 22 de dezembro de 1992, pelo Professor Martín Almada, no bojo do arquivo secreto da polícia política do ditador paraguaio Alfredo Stroessner (ALMADA, 2009, p.218)

${ }^{8}$ Nesse contexto, pode ser indicada a condenação exarada pelo Tribunal Oral en lo Criminal Federal $N^{\circ} 1$ de Buenos Aires, em 27 de maio de 2016, em face dos militares argentinos que colaboraram para a prática de graves violações de direitos humanos no marco da Operação Condor. (CHEHAB; CRUZ, 2016, p. 70-71)

9 Tais provas podem ser exemplificadas, por intermédio das condenações da CorteIDH nos casos seguintes: Goiburú y otros vs. Paraguay (2006) e Gelman vs. Uruguay (2011). (BRASIL, 2014, p. 220)
} 
experiências comuns relacionadas à não-repetição das graves violações de direitos humanos praticadas na vigência das ditaduras latinas, tal qual o ocorrido, por exemplo, com o advento da instalação, em 2005, da Commission for Truth and Friendship ou Comissão Binacional da Verdade de Timor-Leste e da Indonésia.

\section{CONCLUSÃO}

Verificou-se como deveras necessária a retomada das discussões teóricas e das políticas públicas em torno da justiça transicional no Brasil, relegadas a somenos importância, a partir do ano de 2015, uma vez que podem colaborar diretamente para um novo olhar sobre o passado, mas igualmente sobre o presente, com vistas a um futuro genuinamente democrático e propiciador de respostas à altura dos seus desafios. De fato, entende-se que as medidas de transição, se implementadas em consonância com as suas normativas - nacionais e internacionais, sob os auspícios do monitoramento de uma sociedade civil esclarecida, oportunizam novas conexões entre o passado e o presente, inclusive, uma efetiva ressignificação da verdade e da memória no âmbito coletivo.

Por semelhante modo, observou-se que a criação de um órgão federal e permanente de seguimento aos trabalhos desenvolvidos pela Comissão Nacional da Verdade (CNV), pode agregar efetivamente aos debates em torno da justiça de transição, como também pode colaborar para uma práxis democrática voltada para a educação em direitos humanos, de respeito à memória e à verdade e de fortalecimento da temática transicional junto à sociedade civil. Devendo tal iniciativa ser agregada, em caráter mais amplo, à instituição de uma Comissão Regional da Verdade (CRV), com vistas a tratar e investigar as graves violações de direitos humanos cometidas no seio das ditaduras latinas, especialmente àquelas deflagradas no curso das décadas de 60 e 90 do século XX, no marco da Operação Condor, ainda, parcamente discutida, em solos nacionais.

Igualmente, entendeu-se que a reinserção da justiça de transição na agenda de direitos humanos brasileira tende a colaborar para o enfrentamento de desafios, que, embora originados no passado, estão constantemente presentes nos questionamentos relacionados às práticas do Estado democrático de direito brasileiro, a exemplo da concepção reinante de impunidade dos agentes da repressão de outrora, da criminalização dos movimentos sociais e dos defensores de direitos humanos e da desídia estatal para com as graves violações de direitos humanos cometidas hodiernamente. 
Nesses termos, verificou-se da relevância de retomar os estudos em torno da justiça de transição no Brasil, tendo-se em conta que a concretização teórica-prática dos seus pilares de verdade, memória, justiça, reparação e reformas institucionais podem contribuir em demasia para a superação dos legados autoritários de outrora, mas não apenas isto. Podem - e devem colaborar diretamente para a construção de uma democracia mais genuína, porque mais transparente, verdadeira e cônscia dos seus limites e desafios do presente, mas, sobretudo, do porvir.

Por fim, deve-se frisar que os estudos em torno do enfrentamento à solução de continuidade da justiça transicional gozam, a exemplo do vivenciado por nossos vizinhos do Cone Sul, de valia não apenas simbólica, mas também pragmática, haja vista que ao se (re)conhecer e dar ampla visibilidade as graves violações de direitos humanos cometidas durante a ditadura civil-militar brasileira, insta-se também à obrigação estatal de elaborar e implementar mecanismos jurídicos e políticos permanentes para sua não-repetição.

\section{REFERÊNCIAS}

ALMADA, Martin. Operação Condor: conspiração contra a sociedade do conhecimento. In: SILVA, Haike R. Kleber da (Org.). A luta pela anistia. São Paulo: UNESP, 2009.p.217-230.

AMBOS, Kai et al. (Coord.). Justicia de transición: Con informes de América Latina, Alemania, Italia y España. Montevideo: Konrad AdenauerStiftung, 2009.

2009.

. Justiça e memória - para uma crítica ética da violência. São Leopoldo: Unisinos,

BOBBIO, Norberto. O futuro da democracia. Trad. Marco Aurélio Nogueira. São Paulo: Paz e Terra, 2011.

BRASIL. Comissão Nacional da Verdade. Relatório final da CNV. Brasília: CNV, 2014.

Constituição (1988). Constituição da República Federativa do Brasil de 1988.

Brasília, DF, Senado, 1988. Disponível em:. Acesso em: 15 jan. 2017.

. Lei n. 6.683,28 de agosto de 1979. Concede anistia e dá outras providências. Disponível em:<http://www.planalto.gov.br/ccivil_03/leis/L6683.htm.>. Acesso em: 12 jan. 2017.

Lei n. 9.140, de 4 de dezembro de 1995.Reconhece como mortas pessoas desaparecidas em razão de participação, ou acusação de participação, em atividades políticas, no período de 2 de setembro de 1961 a 15 de agosto de 1979, e dá outras providências. Disponível em: . Acesso em: 12 jan. 2017.

Lei $\mathrm{n}^{\mathrm{o}}$ 12.527, de 18 de novembro de 2011. Regula o acesso a informações previsto no inciso XXXIII do art. 5o, no inciso II do § 3o do art. 37 e no §2o do art. 216 da Constituição Federal; altera a Lei no 8.112, de 11 de dezembro de 1990; revoga a Lei no 
11.111, de 5 de maio de 2005, e dispositivos da Lei no 8.159, de 8 de janeiro de 1991; e dá outras providências. Disponível em:. Acesso em: 15 jan. 2017.

Lei $\mathrm{n}^{\circ}$. 12.528, de 18 de novembro de 2011. Cria a Comissão Nacional da Verdade no âmbito da Casa Civil da Presidência da República. Disponível em: . Acesso em: 15 jan.2017.

. Ministério da Justiça. Centro de Referência das Lutas Políticas no Brasil (19641985). Rio de Janeiro, 2011.

. Ministério Público Federal. Câmara de Coordenação e Revisão. Crimes da ditadura militar. Brasília: MPF, 2017

Secretaria de Direitos Humanos da Presidência da República. Programa Nacional de Direitos Humanos (PNDH- 3). Brasília, 2010.

Lei n. 10.559, de 13 de novembro de 2002. Regulamenta o art. 8o do Ato das Disposições Constitucionais Transitórias e dá outras providências. Disponível em:. Acesso em: 10 jan. 2017.

. Secretaria de Direitos Humanos da Presidência da República. Direito à verdade e à memória: Comissão Especial sobre Mortos e Desaparecidos. Brasília: SEDH, 2007.

BRITO, Alexandra Barahona de. Justiça Transicional e a política da memória: uma visão global. In: Revista Anistia Política e Justiça de Transição. Brasília, n. 1, p. 56-83, jan/jun. 2009.

BUZANELLO, José Carlos. Direito de resistência constitucional. Rio de Janeiro: América Jurídica, 2002.

CHEHAB, Isabelle Maria Campos Vasconcelos. A ditadura de toga. In: PFLUG, Samantha Ribeiro Meyer Pflug al. (Coord.). Memória, verdade e justiça de transição. Florianópolis: FUNJAB, 2013.p.114-130.

CHEHAB, Isabelle Maria Campos Vasconcelos; CRUZ, Marco Aurélio Rodrigues da Cunha. Perspectivas e desafios de Comissões Bi ou Plurinacionais da Verdade. In: FERREIRA, Gustavo Assed et. al. (Coord.). Direito internacional dos direitos humanos II. Florianópolis: CONPEDI, 2016.

CRUVINEL, Tereza. Retrocesso: a preocupante intervenção na Comissão de Anistia. Disponível em: . Acesso em: 10 mar. 2017.

D’ARAÚJO, Maria Celina; CASTRO, Celso (Org.). Democracia e Forças Armadas no Cone Sul. Rio de Janeiro: FGV, 2000.

DEL PORTO, Fabíola Brigante. A luta pela anistia no regime militar brasileiro e a construção dos direitos de cidadania. In: SILVA, Haike R. Kleber (Org.). A luta pela anistia. São Paulo: UNESP, 2009. p.59-79.

FICO, Carlos. A negociação parlamentar da anistia de 1979 e o chamado "perdão aos torturadores". Revista Anistia Política e Justiça de Transição, Brasília, n. 4, p. 318-333, jul./dez. 2010.

FREUD, Sigmund. Obras completas. Buenos Aires: Amorrortu, 1989. v. XII. 
GARAPON, Antoine. Crimes que não se podem punir nem perdoar: para uma justiça internacional. São Paulo: Piaget, 2002.

GASPARI, Elio. As ilusões armadas: a ditadura envergonhada. 2 ed. Rio de Janeiro: Intrínseca, 2014.

HAYNER, Priscilla B. Unspeakable truths: transitional justice and the challenge of Truth Commissions. 2. ed. New York: Routledge, 2011.

LEAL, Rogério Gesta. Verdade, memória e justiça no Brasil: responsabilidades compartidas morte, tortura, sequestro e desaparecimento de pessoas no regime militar brasileiro, de quem é a responsabilidade? Porto Alegre: Livraria do Advogado, 2012.

LINZ, Juan J.; STEPAN, Alfred. A transição e consolidação da democracia: a experiência do Sul da Europa e da América do Sul. 2. ed. Trad. Patrícia de Queiroz Carvalho Zimbres. São Paulo: Paz e Terra, 1999.

MINISTÉRIO PÚBLICO FEDERAL - MPF. Disponível em: Acesso em: 20 ago. 2017.

ORGANIZAÇÃO DAS NAÇÕES UNIDAS - ONU. O estado de Direito e a Justiça de Transição em sociedades em conflito ou pós-conflito. Relatório do Secretário-Geral S/2004/616. Revista Anistia Política e Justiça de Transição, Brasília, n.2, p.320-351, jan/jun.2009.

OSMO, Carla. Judicialização da justiça de transição na América Latina = Judicialización de la justicia de transición en América Latina. Trad. Nathaly Mancilla Órdenes. Brasília: Ministério da Justiça, Comissão de Anistia, Rede Latino-Americana de Justiça de Transição (RLAJT), 2016.

PEREIRA, Anthony W. Ditadura e repressão: o autoritarismo e o estado de direito no Brasil, no Chile e na Argentina. Trad. Patrícia de Queiroz Carvalho Zimbres. São Paulo Paz e Terra, 2010.

PINTO, Simone Martins Rodrigues. Direito à memória e à verdade: Comissões de verdade na América Latina. Revista Debates,Porto Alegre, v. 4, n.1, p.128-143, jan./jun. 2010.

SILVA, Haike R. Kleber (Org.). A luta pela anistia. São Paulo: UNESP, 2009.

SOUSA, Jessie Jane Vieira de. Anistia no Brasil: um processo político em disputa. In: PAYNE, Leigh A. et al. A anistia na era da responsabilização: o Brasil em perspectiva internacional e comparada. Brasília: Ministério da Justiça, 2011.p.188-210.

TEITEL, Ruti G. Transitional Justice genealogy. Harvard Human Rights Journal, Cambridge, v.16, p.69-94, spring 2003.

TELES, Edson; SAFATLE, Vladimir (Coord.). O que resta da ditadura: a exceção brasileira. São Paulo: Boitempo, 2010.

ZAMORA, José A. Perdón y política em contextos de justicia transicional. In: BARTOLOMÉ RUIZ, Castor M.M. (Org.). Justiça e memória: direito à justiça, memória e reparação - a condição humana nos estados de exceção. São Leopoldo: Casa Leiria, 2012.p.95-124

ZYL, Paul van. Promovendo a justiça transicional em sociedades pós-conflito. In: REÁTEGUI, Félix. Justiça de transição: manual para a América Latina. Brasília: Comissão de Anistia, Ministério da Justiça; Nova Iorque: Centro Internacional para a Justiça de Transição, 2011. p. 47-72. 